\title{
Maternal and neonatal outcome in pregnancy with previous lower segment caesarean section undergoing trial of scar
}

\author{
Monika Dalal $^{1 *}$,Smiti Nanda1 ${ }^{1}$ Jagjit S. Dalal ${ }^{2}$, Samiksha Kaushik ${ }^{1}$, Meenakshi Chauhan', \\ Vani Malhotra $^{1}$, Sushila Chaudhary ${ }^{1}$, Vandana Rani ${ }^{1}$, Parul Singh ${ }^{1}$
}

\begin{abstract}
${ }^{1}$ Department of Obstetrics and Gynaecology, ${ }^{2}$ Department of Neonatology, Pt. B. D. Sharma Post Graduate Institute of Medical Sciences, Rohtak, Haryana, India
\end{abstract}

Received: 23 June 2021

Revised: 23 July 2021

Accepted: 26 July 2021

\author{
*Correspondence: \\ Dr. Monika Dalal, \\ E-mail: drmonikadalal@gmail.com
}

Copyright: (c) the author(s), publisher and licensee Medip Academy. This is an open-access article distributed under the terms of the Creative Commons Attribution Non-Commercial License, which permits unrestricted non-commercial use, distribution, and reproduction in any medium, provided the original work is properly cited.

\begin{abstract}
Background: Women with previous LSCS often have to make a decision about mode of delivery of their second baby. As the rate of caesarean section is continuously increasing, vaginal birth after caesarean section (VBAC) is a good strategy to decrease caesarean rate. The present study was planned to assess the fetomaternal outcome in pregnancies with previous lower segment caesarean section undergoing trial of scar and to identify the factors, which can influence the outcome of trial of scar.

Methods: This was a prospective observational study on 100 patients at a tertiary care institute. Pregnant women with previous LSCS were selected randomly for the study on the basis of the inclusion and exclusion criteria. Each labor monitored closely using a partogram. Decision for repeat emergency caesarean was taken by consultant. All women included in the study were followed through delivery and till discharge.

Results: Out of 100 pregnant women $49 \%$ cases had successful VBAC, 50\% had emergency caesarean and one patient had laparotomy for rupture uterus. In women, who also had a prior vaginal delivery, $72 \%$ delivered vaginally, as compared to $40 \%$ of the women who did not undergo prior vaginal delivery ( $p$ value $=0.003$ ). Women who were in spontaneous labor, $59.21 \%$ delivered vaginally, whereas women who were induced, $16.6 \%$ delivered vaginally. The rate of perinatal complication was more in the patients who required an emergency CS after a failed trial.

Conclusions: Our findings may encourage obstetricians to encourage VBAC in the properly screened ANC patients and decrease the rate of recommending caesarean section.
\end{abstract}

Keywords: Previous lower segment caesarean section, Pregnancy, Vaginal birth after caesarean section, Trial of scar

\section{INTRODUCTION}

Caesarean section is the most commonly performed surgery in obstetrics with section rate steadily increasing from $5 \%$ to $25 \% .^{1}$ As the rate of caesarean section is continuously increasing, vaginal birth after caesarean section (VBAC) is a good strategy to decrease caesarean rate. It is a trial of vaginal delivery in selected cases of previous lower segment caesarean section (LSCS) in a well-equipped hospital. ${ }^{2}$ Women with previous LSCS often have to make a decision about mode of delivery of their second baby. Typically, they will be offered the choice of having an elective repeat caesarean section (ERCS) or vaginal birth after caesarean section (VBAC). Scarred uterus is always a concern for pregnant woman as well as obstetrician as it leads to increased maternal and perinatal morbidity. ERCS are associated with increased operative blood loss, bladder and ureteral injuries, postpartum infections, pulmonary embolisms, 
and neonatal respiratory complications. Multiple repeat CSs can lead to increased risk of maternal morbidity and mortality as a result of abnormal placental adherence and caesarean hysterectomy. ${ }^{2}$

VBAC section has less complications and faster recovery compared with elective repeat CS. But there has been increasing concern about the risk of uterine rupture associated with trial of labour after previous Caesarean. The ability to predict the outcome of an attempted trial of scar plays an important role in initial counselling of pregnant women with previous one caesarean delivery. ${ }^{3}$ Many studies have been conducted regarding factors affecting the outcome of VBAC like previous successful vaginal deliveries, interval between previous Caesarean and current pregnancy, indication of previous caesarean, postoperative wound sepsis etc., but no standard guidelines has been formed for patients of previous caesarean section to attempt VBAC. $^{4}$ So, the present study was planned to assess the maternal and neonatal outcome in pregnancies with scarred uterus and to identify the factors, which can influence the outcome of trial of scar.

\section{METHODS}

This study was a prospective observational study on 100 patients over a period of 6 months (December 2020 to May 2021). Pregnant women with previous LSCS presenting in the department of obstetrics and gynecology at Pandit B. D. Sharma post graduate institute of medical sciences, Rohtak were selected randomly for the study on the basis of the selection criteria after detailed counselling (Figure 1).

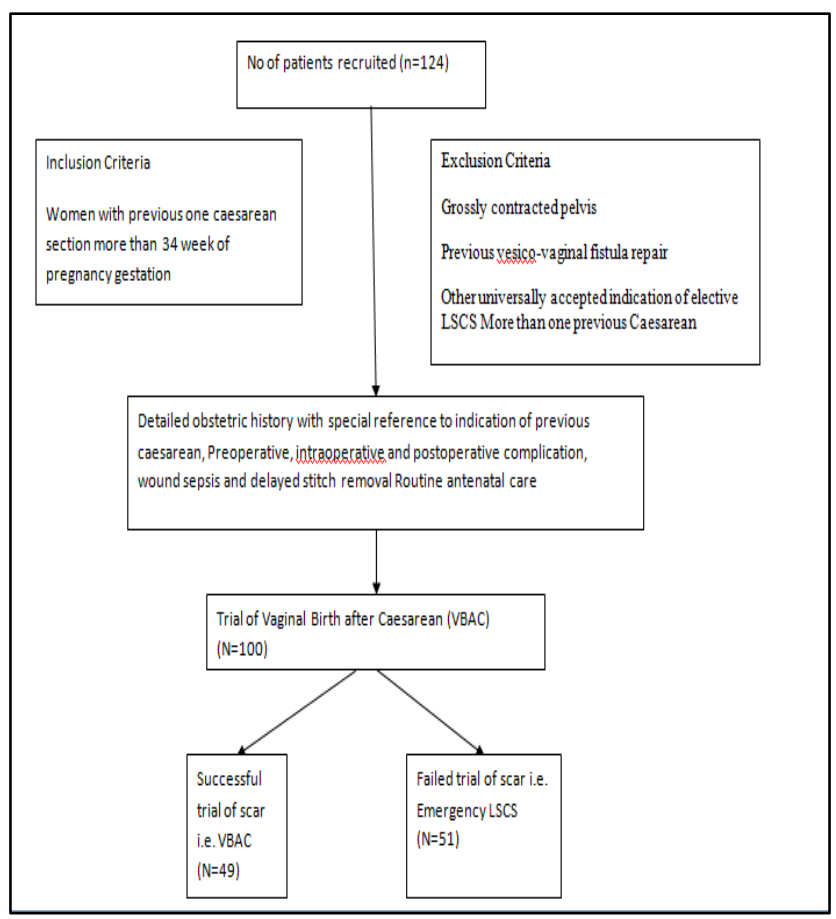

Figure 1: Study consort.

\section{Inclusion criteria}

Inclusion criterion for current study was all women who were more than 34 week of gestation with previous one LSCS coming for delivery.

\section{Exclusion criteria}

Exclusion criterion for current study were; associated medical disorder like pregnancy induced hypertension, diabetes, heart disease and renal disease, women with a uterine scar of myomectomy, previous classical caesarean section, history of uterine rupture, women with malpresentation, contraindications to vaginal delivery like cephalopelvic disproportion, major degree placenta praevia, and transverse lie and women not giving consent for vaginal birth after caesarean section.

Informed consent was taken from enrolled patients. They were provided with written and verbal information including the potential risk involved in the research. Data was collected using a proforma. It included bio data, socio-demographic characteristics, and detailed obstetric history with special reference to indication of previous caesarean, preoperative, intraoperative and postoperative complication. Risks and benefits of the VBAC was explained in native language. The mode of delivery was decided according to the routine hospital protocol by the consultant. Each labor monitored closely using a partogram and regular auscultation of the fetal heart at least once every 30 minutes. For induction of labor, cervical ripening was done as per hospital protocols by intra cervical catheter or single dose of tab mifepristone $400 \mathrm{mg}$ and the entire process of induction was physically monitored by a senior obstetrician. Syntocinon was used in few patients who needed augmentation. Decision for repeat emergency caesarean was taken by consultant. All women included in the study were followed through delivery and till discharge. Maternal and perinatal outcomes were compared between women who had successful VBAC and those who had failed VBAC.

\section{Primary and secondary outcome}

Primary outcome of current study was delivery outcome in the index pregnancy and secondary outcome was maternal and perinatal complications.

\section{Statistical analysis}

Descriptive statistics were used to analyze the continuous and categorical data, while proportions were analyzed using Chi-square test, $\mathrm{p} \leq 0.05$ was considered statistically significant.

\section{RESULTS}

Present study was conducted in the Pandit B. D. Sharma postgraduate institute of medical sciences, Rohtak after 
an ethical committee approval. It's a tertiary care teaching hospital in the northern region of India. Total 124 mothers with one previous caesarean section who reported in our institute were primarily screened and 100 pregnant women were included in the study for VBAC, remaining were excluded depending on the exclusion criteria. The variables studied were the age, mode of delivery, factors affecting the mode of delivery, maternal and fetal outcomes and duration of hospital stay. The majority of the patients were spread over the age group of 20-35 years with the maximum number in the 20-25 age group. It has been observed that women belonging to 30 35 age group had maximum successful vaginal delivery. Majority of patients (75\%) were in their second pregnancy, 16 percent in third pregnancy and 9 percent were in fourth pregnancy (Table 1).

Table 1: Demographic profile $(n=100)$.

\begin{tabular}{|lllll|}
\hline Characteristics & $\mathbf{N}$ & $\begin{array}{l}\text { Successful VD } \\
\mathbf{N}(\%)\end{array}$ & $\begin{array}{l}\text { Emergency repeat C/S } \\
\mathbf{N}(\%)\end{array}$ & $\begin{array}{l}\text { Rupture uterus } \\
\mathbf{N}(\%)\end{array}$ \\
\hline Maternal age (years) & & & $1(33.3)$ & - \\
\hline$<20$ & 3 & $2(66.66)$ & $26(50)$ & $1(1.92)$ \\
\hline $20-25$ & 52 & $25(48.07)$ & $16(59.25)$ & - \\
\hline $26-30$ & 27 & $11(40.74)$ & $5(35.71)$ & - \\
\hline $31-35$ & 14 & $9(64.28)$ & $2(50)$ & 1 \\
\hline$>35$ & 4 & $2(50)$ & 50 & $1(1.33)$ \\
\hline Total & 100 & 49 & & - \\
\hline Parity & & & $44(58.66)$ & - \\
\hline Para 1 & 75 & $30(40)$ & $4(25)$ & \\
\hline Para 2 & 16 & $12(75)$ & $2(22.22)$ & \\
\hline$\geq$ para 3 & 9 & $7(77.77)$ & & \\
\hline
\end{tabular}

Out of 100 cases who were given trial of labour, $49 \%$ cases had successful VBAC; 42 with episiotomy, 5 with ventouse and 2 with forceps. Total no. of LSCS done for failed trial of labour in given study period were 50 . One laparotomy was done for rupture uterus leading to still birth (Figure 2).

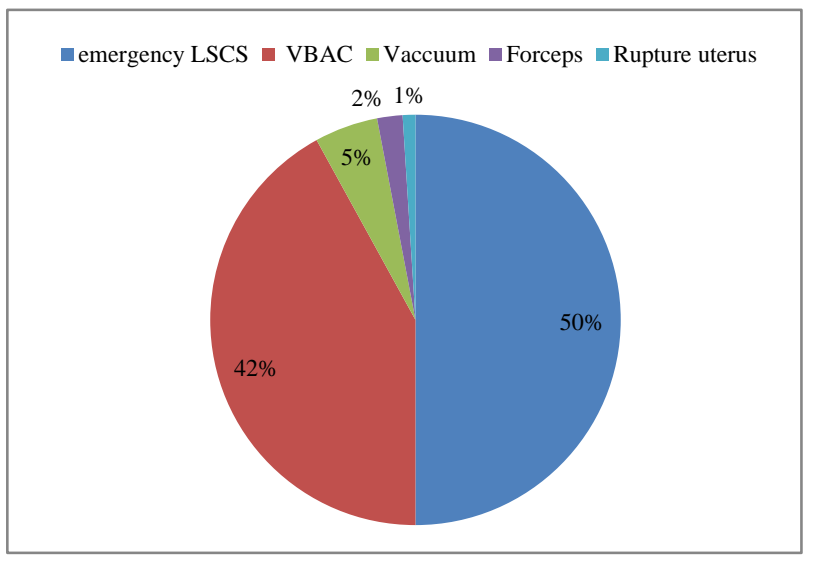

Figure 2: Outcome of trial of scar.

On assessment of cause of previous caesarean section in the previous pregnancy and outcome of the present labour, it was observed that all the patients who underwent caesarean section due to fetal distress and transverse lie in the previous pregnancy has a highest success rate than other causes. Out of the 55 patients who were operated for fetal distress in last pregnancy 33 delivered vaginally and 22 required an emergency LSCS. Repeat Caesarean section was significantly more common in patients who had failure to progress as the indication of previous caesarean (Table 4). VBAC was successful in 57.14 percent of the patients who required an elective LSCS in the previous pregnancy (Table 2).

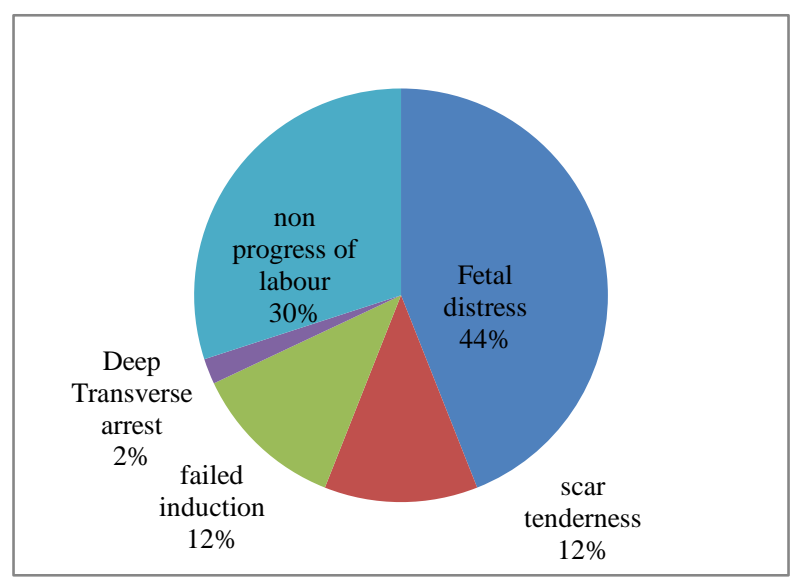

Figure 3: Indication of repeat caesarean.

There was significant association between previous vaginal delivery and outcome of TOS, $72 \%$ of the women with previous caesarean section, who also had a prior vaginal delivery, delivered vaginally, as compared to $40 \%$ of the women who did not undergo prior vaginal delivery $(p=0.003)$ (Table 3 ). Out of the 76 women who were in spontaneous labor, $59.21 \%$ delivered vaginally, whereas out of the 24 who were induced, $16.6 \%$ delivered vaginally $(p=0.0001)$. The chief methods of induction used were oxytocin, cervical ripening balloon, and mifepristone (Table 4). When outcome of labour was assessed with respect to the birth weight of the baby, it was found that if the birth weight of baby is less than 3 $\mathrm{kg}$, the chances of VBAC were $52.56 \%$ while chances of 
VBAC is less if baby weight $>3 \mathrm{~kg}(36.36 \%)$. This suggests that increasing birth weight is associated less chances of successful VBAC (Table 5). Out of 100 women, $50 \%$ women ended up in emergency caesarean deliveries and in 1 case there was rupture uterus. Fetal distress was the main indication in $44 \%$ women while the second common cause was failure to progress in $30 \%$ of cases (Figure 3).

Table 2: Indications for previous caesarean section and outcome of labour in present pregnancy.

\begin{tabular}{|llllllll|}
\hline $\begin{array}{l}\text { Indication of previous caesarean } \\
\text { section }\end{array}$ & $\mathbf{N}$ & Vaginal delivery & $\%$ & C.S & $\%$ & Rupture uterus & Rate \% \\
\hline Fetal distress & 55 & 30 & 54.54 & 25 & 45.45 & - & - \\
\hline Breech & 18 & 9 & 50 & 9 & 50 & - & - \\
\hline Failure to progress & 17 & 4 & 23.52 & 12 & 70.58 & 1 & 5.8 \\
\hline Transverse lie & 6 & 4 & 66.66 & 2 & 33.33 & - & - \\
\hline APH & 4 & 2 & 50 & 2 & 50 & - & - \\
\hline Outcome in relation to type of LSCS in previous pregnancy & & & & & \\
\hline Emergency & 79 & 37 & 46.83 & 42 & 51.89 & - & - \\
\hline Elective & 21 & 12 & 57.14 & 8 & 38.09 & 1 & 4.76 \\
\hline
\end{tabular}

Table 3: outcome of labour in relation to previous vaginal delivery/VBAC.

\begin{tabular}{|llll|}
\hline Parameters & Total & $\begin{array}{l}\text { Successful trial of scar (VBAC) } \\
\mathbf{N}(\%)\end{array}$ & $\begin{array}{l}\text { Failed trial of scar (emergency } \\
\text { caesarean) } \mathbf{N}(\%)\end{array}$ \\
\hline $\begin{array}{l}\text { No H/O previous vaginal delivery or } \\
\text { VBAC }\end{array}$ & 75 & $30(40)$ & $45(60)$ \\
\hline H/O previous vaginal birth & 25 & $18(72)$ & $7(28)$ \\
\hline
\end{tabular}

Table 4: Mode of onset of labour and delivery outcome in women who underwent trial of scar.

\begin{tabular}{|lllll|}
\hline $\begin{array}{l}\text { Onset of } \\
\text { labour }\end{array}$ & Method of induction & $\mathbf{N}$ & Mode of delivery: vaginal (\%) & $\begin{array}{l}\text { Failed trial of scar } \\
(\%)\end{array}$ \\
\hline \multirow{4}{*}{ Induced } & Mifepristone & 12 & 2 & 10 \\
\cline { 2 - 6 } & Foley's catheter & 3 & 0 & 3 \\
\cline { 2 - 5 } & Mife+foley's catheter & 8 & 1 & 7 \\
\cline { 2 - 5 } & Oxytocin & 1 & 1 & - \\
\cline { 2 - 5 } & Total & 24 & $4(16.6)$ & $20(83.33)$ \\
\hline Spontaneous & & 76 & $45(59.21)$ & $31(40.78)$ \\
\hline
\end{tabular}

Table 5: Outcome of labour according to birth weight.

\begin{tabular}{|c|c|c|c|}
\hline $\begin{array}{l}\text { Birth } \\
\text { weight } \\
\text { (kg) }\end{array}$ & $\mathbf{N}$ & $\begin{array}{l}\text { Vaginal } \\
\text { delivery N (\%) }\end{array}$ & $\begin{array}{l}\text { Failed trial of } \\
\text { scar N (\%) }\end{array}$ \\
\hline$\leq 3$ & 78 & $41(52.56)$ & $37(47.43)$ \\
\hline$>3$ & 22 & $8(36.36)$ & $14(63.63)$ \\
\hline
\end{tabular}

Perinatal outcome in both the groups is depicted in table 5 . In our study there were only 2 cases where the APGAR score was less than 6 in the patients who delivered vaginally. The rate of complication was more in the patients who required an emergency CS after a failed trial. In 9 patients APGAR score was less than 6, there were 1 still births, 1 neonatal death and 1 baby had sepsis. Only 1 case in emergency LSCS had APGAR <6 even at 5 minutes. This suggests that the rate of perinatal morbidity and mortality was higher in the patients requiring emergency caesarean section (Table 6). In failed trial of scar group, there was one case of rupture uterus; adhesions between omentum, bowel \& bladder was seen in $25.49 \%$ cases (Table 7). In vaginally delivered patients, there was only one case of scar site rupture after successful vaginal delivery and only 1 case each of cervical, vaginal and paraurethral tear (Table 10). The average hospital stay increased with instrumentation and the repeat CS. Average hospital stay in the patients who delivered by spontaneous vaginal delivery, instrumental vaginal delivery and repeat CS was 2.2, 3.5 and 5.7 days respectively. This shows that women who had a successful VBAC had a significantly lesser duration of hospital stay as compared to those had a caesarean section

\section{DISCUSSION}

This study was conducted with the main objective of identifying factors associated with successful vaginal delivery in the mothers offered vaginal birth after previous lower segment caesarean section. As there is significant rise in the incidence of primary CS for various 
indications, an increasing proportion of the pregnant women report with a history of a previous CS.

Table 6: Fetal outcome of patient for trial of scar.

\begin{tabular}{|c|c|c|c|c|c|c|c|}
\hline \multirow[b]{2}{*}{$\begin{array}{l}\text { Outcome of trial of } \\
\text { scar }\end{array}$} & \multirow[b]{2}{*}{ Route of delivery } & \multirow[b]{2}{*}{ Total } & \multicolumn{2}{|l|}{ Mortality } & \multicolumn{3}{|l|}{ Morbidity } \\
\hline & & & Still birth & $\begin{array}{l}\text { Neonatal } \\
\text { death }\end{array}$ & Jaundice & Sepsis & APGAR $<6$ \\
\hline \multirow{2}{*}{ Failed trial of scar } & Caesarean section & 50 & - & 1 & 1 & 1 & 9 \\
\hline & Rupture uterus & 1 & 1 & & & & \\
\hline \multirow{3}{*}{ Successful trial of scar } & VBAC & 42 & - & & 1 & & \\
\hline & Vacuum & 5 & - & & & & 1 \\
\hline & Forceps & 2 & - & & 1 & & 1 \\
\hline Total & & 100 & 1 & 1 & 3 & 1 & 11 \\
\hline
\end{tabular}

Table 7: Complication.

\begin{tabular}{|ll|}
\hline Parameters & Frequency (\%) \\
\hline Complication after failed trial of scar & $(\mathbf{N}=\mathbf{5 1})$ \\
\hline Rupture uterus & $1(1.96)$ \\
\hline Scar dehiscence & $1(1.96)$ \\
\hline Scar thinned out & $8(15.68)$ \\
\hline $\begin{array}{l}\text { abdominal wall, bladder, omental } \\
\text { adhesion }\end{array}$ & $13(25.49)$ \\
\hline Prolonged catheterization & $4(7.84)$ \\
\hline Post partum hemorrhage & $3(5.88)$ \\
\hline Wound gape & $6(11.76)$ \\
\hline $\begin{array}{l}\text { Complication after VBAC/successful trial of scar } \\
\text { (N=49) }\end{array}$ & $1(2.04)$ \\
\hline Scar site rupture & $1(2.04)$ \\
\hline Cervical tear & $1(2.04)$ \\
\hline Vaginal tear & $1(2.04)$ \\
\hline Paraurethral tear & \\
\hline
\end{tabular}

These women are always in a high risk group due to the risk of a scar rupture. Uterine rupture is an extremely dangerous event causing serious harm to the pregnant woman as well as the baby. This is the most important risk involved, but the advantage of the vaginal delivery largely outweighs the risks associated with a repeat CS. ${ }^{2,5,6}$ Dhillon and associates reported a success rate of $62.3 \%$ in those who had trial of labour and Singh $\mathrm{N}$ et al reported a success rate of $67.6 \% .^{7,4}$ Kaur et al has reported $59.17 \%$ of women with previous CS undergoing trial of labor had vaginal delivery. ${ }^{2}$

In present study $49 \%$ of patients had a successful VBAC, which is lower than that in other studies but comparable to Aisien et al, who reported a $48.1 \%$ incidence of vaginal delivery in previous caesarean section cases. ${ }^{8}$ Padmasree et al reported $40.32 \%$ of patients had a successful VBAC. ${ }^{9}$ The probable reason for low rate of successful VBAC in our study was that most of the patients who opted for a trial of labour did not have history of prior vaginal deliveries.

As reported in literature, there is significant association between previous vaginal delivery with a higher rate of successful trial of scar (TOS) compared with patients with no prior vaginal delivery. ${ }^{10,11}$ In our study there was a success rate of $72 \%$ for patients with history of previous vaginal delivery in comparison to $40 \%$ success rate in patients with no history of previous vaginal delivery. These results correlate well with the study by Balachandran et al and Landon et al., and support the fact that the history of a previous normal vaginal delivery is the most important predictor for a successful VBAC. ${ }^{3,12}$ A lower success rate of vaginal delivery was also reported by them for women with induced labour compared to those who presented in spontaneous labor which is again in agreement with our results.

Devkare et al highlighted the better chances of VBAC for average-sized babies $(66.2 \%)$ compared to babies weighing more than $3 \mathrm{~kg}(20 \%) .{ }^{13}$ Balachandran and coworkers also stated that there are lower chances of successful vaginal delivery with increasing neonatal baby weight. ${ }^{3}$ In our study we observed success rate of VBAC for average sized baby was $52.56 \%$ in comparison to $36.36 \%$ for babies weighing more than $3 \mathrm{~kg}$. One case of rupture uterus was also observed in more than $3 \mathrm{~kg}$ group. So the trial of the VBAC should be given cautiously in the patients with expected fetal weight more than $3 \mathrm{~kg}$. It was observed in our study that fetal mortality and morbidity was higher in the patients in whom there is failure of trial of scar. In the failed trial of scar group, there were 1 case of still birth, 1 case of neonatal death and in 9 cases the APGAR score was less than 6 while in vaginal delivery group there was no still birth or neonatal death and only 2 babies had APGAR score less than 6 . Devkare et al also observed similar finding with 2 cases of still birth and neonatal death each and 9 cases of APGAR less than six. ${ }^{13}$ While the long-term predictive value of APGAR scores is low, it is an established and accepted part of the neonatal assessment at the time of delivery. Our findings reinforce similar previous studies suggesting that vaginal delivery after one caesarean section is safe as regards neonatal outcomes. ${ }^{14-16}$

While doing a repeat caesarean section the main difficulty was adhesions between omentum, peritoneum and bladder in $25.49 \%$ of the cases which is comparable to Mishra et al study (26.98\%) and padamsree et al $(25.62 \%) .{ }^{17,9}$ Important complications in failed trial of scar group were rupture uterus $(1.96 \%)$, scar dehiscence 
$(1.96 \%)$, thinned out scar $(15.68 \%)$, wound gape $(11.76 \%)$, prolonged catheterization $(7.84 \%)$, postpartum hemorrhage (PPH) $(5.88 \%)$ etc. The rate of complications in our study is comparable to Mishra et al study. The maternal complications and perinatal morbidity in successful trial of scar group was similar to those seen with other normal vaginal deliveries with the exception of scar site rupture in one case. That patient had PPH and scar site repair was done after laparotomy. Only 3 cases had minor morbidities like hematoma of vaginal tear, cervical tear and paraurethral tear. It has generally been accepted that vaginal delivery is associated with lower maternal morbidity and mortality rates than repeat caesarean section.

After comparing hospital stay of the VBAC and Emergency repeat caesarean it was found that the average length of hospital stay was less in vaginal delivery than the CS. Similar results were reported by other studies. $^{13,18-20}$ Decreased hospital stay is beneficial for both patients and hospitals. It also means that there are less complications and less expenditure of the government on the healthcare of pregnant women. The strengths of our study were the methodology, the use of inclusion and exclusion criteria.

\section{Limitations}

Limitations of current study were; sample size was small. This study was done in single center. A multi-centric study might be able to give a better picture. Correlation of the factors affecting success of VBAC trial with scar rupture could not be made due to small sample size and scarcity of adverse events like scar dehiscence.

\section{CONCLUSION}

Spontaneous labour and prior vaginal delivery are associated with successful VBAC in women with a single prior low transverse caesarean delivery. However failed trial of VBAC has more maternal infectious morbidity and lower APGAR scores. Our findings may encourage obstetricians to encourage VBAC in the properly screened ANC patients and decrease the rate of recommending caesarean section.

Funding: No funding sources Conflict of interest: None declared

Ethical approval: The study was approved by the Institutional Ethics Committee

\section{REFERENCES}

1. Marc HI. Operative Delivery. In: DeCherney AH, Nathan L, Laufer N, Roman AS eds. Current diagnosis and treatment obstetrics and gynecology; 10th ed. New York NY: McGraw-Hill; 2007:461-76.

2. Kaur J. A Retrospective study to evaluate maternal and fetal outcome in vaginal birth after caesarian section. J Adv Med Dent Scie Res. 2019;7(5):102-5
3. Balachandran L, Vaswani PR, Mogotlane R. Pregnancy outcome in women with previous one Caesarean Section. J Clin Diagnos Res. 2014;8(2): 99-102.

4. Singh N, Tripathi R, Mala YM. Maternal and Foetal Outcomes in Patients with previous caesarean section undergoing trial of vaginal birth at a tertiary care centre in North India. J Preg Child Health. 2014;1: 102.

5. Nair M, Kurinczuk JJ, Knight M. Establishing a national maternal morbidity outcome indicator in England: A Population-based study using routine hospital data. PLoS One. 2016;11:e0153370.

6. García-Benítez CQ, López-RiojaMde J, MonzalboNúñez DE.Vaginal birth after caesarean A safe option?. Ginecol Obstet Mex. 2015;83:69-87.

7. Dhillon BS, Chandhiok N, Bharti S, Bhatia P, Coyaji KJ, Das MC, et al. Vaginal birth after caesarean section (VBAC) versus emergency repeat caesarean section at teaching hospitals in India: an ICMR task force study. Int J Reprod Contracept Obstet Gynecol. 2014;3:592-7.

8. Aisien AO, Oronsaye AU. Vaginal birth after one previous caesarean section in a tertiary institute in Nigeria. J Obstet Gynecol. 2004;24(8):886-90.

9. Padmasree I, Rama Kishore AV. Fetomaternal outcome of pregnancy with previous caesarean section at tertiary care hospital. Ind J Applied Research. 2020;10(1):15-7.

10. Hendler I, Bujold E. Effect of prior vaginal delivery or prior vaginal birth after caesarean delivery on obstetric outcomes in women undergoing trial of labour. Obstet Gynecol. 2004;104(2):273-7.

11. Caughey AB, ShippTD, Repke JT. Trial of labour after caesarean delivery: the effect of previous vaginal delivery. Am J Obstet Gynecol. 1998;179(4): 938-41.

12. Landon MB, Hauth JC, Leveno KJ, et al. Maternal and perinatal outcomes associated with a trial of labour after prior caesarean delivery. N Engl J Med. 2004;351:2581-9.

13. Devkare V, Agarwal NV, Gayakwad N, Kamant S. Maternal and fetal outcome of VBAC after first previous LSCS in a tertiary care teaching hospital of Western India. Int J Curr Res Med Sci. 2017;3(7):817.

14. Macones GA, Peipert J, Nelson DB, et al. Maternal complications with vaginal birth after caesarean delivery: a multicenter study. Am J Obstet Gynecol. 2005; 193:1656-62.

15. Colm OH. VBAC outcome associated with standardized intra12. partum protocol after one previous caesarean. Am J Obstet Gynecol. 2005;193: 546.

16. Frass KA. and. AlHarazi AH Outcome of vaginal birth after caesarean section in women with one previous section and spontaneous onset of labour. EMHJ. 2011;17 (8):646-50. 
17. Mishra N, Taori N, Misri A. Fetomaternal Outcome of Pregnancy with Previous Caesarean Section. J Evol Dent Sci. 2014;3(47):11369-78.

18. MacDorman M, Declercq E, Menacker F. Recent trends and patterns in caesarean and vaginal birth after caesarean (VBAC) deliveries in the United States. Clin Perinatol. 2011;38:179-92.

19. Homer CS, Johnston R, Foureur MJ. Birth after caesarean section: changes over a nine- year period in one Australian state. Midwifery. 2011;27:165-9.

20. Birara M, Gebrehiwot Y. Factors associated with success of vaginal birth after one caesarean section
(VBAC) at three teaching hospitals in Addis Ababa, Ethiopia: a case control study. BMC. 2013;13:31.

Cite this article as: Dalal M, Nanda S, Dalal JS, Kaushik S, Chauhan M, Malhotra V, et al. Maternal and neonatal outcome in pregnancy with previous lower segment caesarean section undergoing trial of scar. Int J Reprod Contracept Obstet Gynecol 2021;10:3434-40. 